\title{
Corrosion Protection of Carbon Steel by Pongamia glabra Oil- Based Polyetheramide Coatings
}

\author{
Manawwer Alam ${ }^{1, *}$, Naser M Alandis ${ }^{2}$, Naushad Ahmad $^{2}$, Mohammad Asif Alam $^{3}$ \\ ${ }^{1}$ Research Centre-College of Science, King Saud University, P.O. Box 2455, Riyadh 11451, Saudi \\ Arabia \\ ${ }^{2}$ Department of Chemistry, College of Science, King Saud University, P.O. Box 2455, Riyadh 11451, \\ Saudi Arabia \\ ${ }^{3}$ Center of Excellence for Research in Engineering Materials, Advanced Manufacturing Institute \\ (AMI), King Saud University, P. O. Box 800, Al-Riyadh 11421, Saudi Arabia \\ *E-mail: malamiitd@gmail.com
}

doi: $10.20964 / 2018.03 .52$

Received: 27 September 2017 / Accepted: 4 January 2018 / Published: 5 February 2018

\begin{abstract}
Application of electrochemical techniques for corrosion studies of polyetheramide (PEtA) coatings on carbon steel is considered using electrochemical impedance spectroscopy (EIS) and potentiodynamic polarization studies, which are powerful techniques to better, understand the fundamental process of corrosion. In this paper, these techniques are discussed in detail as complementary approaches to understand the complex nature of coating degradation. The PEtA coating was synthesized from a Pongamia glabra oil-based fatty amide diol and bisphenol A. The synthesis was confirmed by Fourier transform infrared spectroscopic techniques. The PEtA coatings were applied on carbon steel strips and their physico-mechanical properties, such as scratch hardness, impact, conical mandrel, and pencil hardness tests, were characterized by standard methods. The surface morphology of the coatings was observed by scanning electron microscopy, and their thermal stability was assessed by thermogravimetric analysis. The anticorrosion properties of PEtA were assessed in a $3.5 \mathrm{wt} \% \mathrm{NaCl}$ solution at room temperature using potentiodynamic polarization and EIS techniques. The PEtA coatings exhibit good physico-mechanical and anticorrosive properties for applications up to $350{ }^{\circ} \mathrm{C}$.
\end{abstract}

Keywords: polyetheramide; coatings; potentiodynamic; corrosion; EIS.

\section{FULL TEXT}

(C) 2018 The Authors. Published by ESG (www.electrochemsci.org). This article is an open access article distributed under the terms and conditions of the Creative Commons Attribution license (http://creativecommons.org/licenses/by/4.0/). 